\title{
Yard waste prediction from estimated municipal solid waste using the grey theory to achieve a zero-waste strategy
}

\author{
Md Rakibul Islam ${ }^{1} \cdot$ Golam Kabir $^{2}$ (D) Kelvin Tsun Wai $\mathrm{Ng}^{3} \cdot$ Syed Mithun $\mathrm{Ali}^{4}$
}

Received: 2 December 2021 / Accepted: 8 February 2022 / Published online: 16 February 2022

(c) The Author(s), under exclusive licence to Springer-Verlag GmbH Germany, part of Springer Nature 2022

\begin{abstract}
Yard waste is one of the key components of municipal solid waste and can play a vital role in implementing zero-waste strategy to achieve sustainable municipal solid waste management. Therefore, the objective of this study is to predict yard waste generation using the grey theory from the predicted municipal solid waste generation. The proposed model is implemented using municipal solid waste generation data from the City of Winnipeg, Canada. To identify the generation factors that influence municipal solid waste generation and yard waste generation, a correlation analysis is performed among eight socio-economic factors and six climatic factors. The GM $(1,1)$ model is utilized to predict individual factors with overall MAPE values of $0.06 \%-10.39 \%$ for the in-sample data, while the multivariable GM $(1, \mathrm{~N})$ grey model is employed to forecast the quarterly level of municipal solid waste generation with overall MAPE values of 5.64\%-7.54\%. In this study, grey models predict quarterly yard waste generation from the predicted municipal solid waste generation values using only twelve historical data points. The results indicate that the grey model (based on the error matrices) performs better than the linear and nonlinear regression-based models. The outcome of this study will support the City of Winnipeg's sustainable planning for yard waste management in terms of budgeting, resource allocation, and estimating energy generation.
\end{abstract}

Keywords Municipal solid waste $\cdot$ Yard waste $\cdot$ Zero waste strategy $\cdot$ GM $(1,1)$ model $\cdot$ GM $(1, N)$ model

\section{Introduction}

Responsible Editor: Marcus Schulz

Golam Kabir

golam.kabir@uregina.ca

Md Rakibul Islam

rbn_khan@yahoo.com

Kelvin Tsun Wai Ng

kelvin.ng@uregina.ca

Syed Mithun Ali

syed.mithun@gmail.com

1 Department of Industrial \& Production Engineering, Rajshahi University of Engineering \& Technology, Rajshahi, Bangladesh

2 Industrial Systems Engineering, University of Regina, Regina, SK, Canada

3 Environmental Systems Engineering, University of Regina, Regina, SK, Canada

4 Department of Industrial and Production Engineering, Bangladesh University of Engineering and Technology, Dhaka, Bangladesh
Solid waste management (SWM) constitutes a challenging and prevalent issue for authorities due to health problems wrought by improper waste management and the various related atmospheric issues, such as odour pollution, air pollution, and soil degradation (Ferronato et al. 2021). In developed countries with growing populations and economies, there has been a steady increase among both urban and rural populations in the level of waste generation (Kamarehie et al. 2020; Llanquileo-Melgarejo \& Molinos-Senante 2021). This increase has made researchers highly concerned about the sustainable management of municipal solid waste (MSW) (Xiao et al. 2020). In response to this issue, many cities-including Adelaide, San Francisco, and Vancouver-have adopted a zero-waste strategy (ZWS) as part of their waste-management system (Ayeleru et al. 2018; Zaman 2015). ZWS is a concept aimed at resource recovery and the conservation of scarce natural resources, as waste is being diverted from landfills for permanent disposal. This strategy can be achieved by minimizing, composting, recycling, and reusing waste and modifying the ways in which people 
and businesses use limited resources; additionally, it urges businesses to product designing so that waste can be eliminated from manufacturing processes (Lombardi and Bailey 2015; Moazzem et al. 2021). In addition, ZWS supports a circular economy (Kurniawan et al. 2021), which can be defined as an economic structure aimed at the reduction of waste and the consistent recycling of energy (Cocker and Graham 2019). To construct a closed-loop structure, circular systems encourage reuse, sharing, maintenance, refurbishment, remanufacturing, and recycling to minimize the use of resource inputs and limit deforestation, carbon emissions, and the generation of waste (Pecorini et al. 2020; Rathore and Sarmah 2020). Like SWM, one of its key components, yard waste management is also becoming increasingly popular among cities in developed countries in the pursuit of a ZWS. Yard waste accounted for $11-27 \%$ of total MSW in urban centres across Australia, Canada, and the USA (Lee et al. 2020; Vu et al. 2019).

The accurate prediction of MSW plays a significant role in the development of a sustainable and efficient waste management system (Ferronato et al. 2020; Singh and Satija 2016). If MSW predictions are inaccurate, waste management programs and facilities can be designed or operated inefficiently (Vu et al. 2019). The univariate prediction of MSW is challenging, as it relies on a wide array of multivariate factors. Population, per capita gross domestic product (GDP), household income, urbanization, standard-of-living parameters, geographical location, climate, and local environmental laws all influence waste generation (Boumanchar et al. 2019; Wang et al. 2018). However, the scarcity of reliable data constitutes a major challenge for the implementation of waste management (Mohammadi et al. 2019).

Compared to other industrialized nations, Canada produced more MSW per capita and diverted less waste to landfills (Pan et al. 2019; Richter et al. 2018). This study uses the CoW as its study area because yard waste accounted for a mean of $25 \%$ of the total MSW reported in the CoW (CoW-a 2020a) from 2007 to 2018. On October 19, 2011, the Winnipeg City Council approved a holistic waste management strategy; it raised the city-wide waste-diversion rate to $50 \%$ or higher, a proposal first made for the public sector by the City Council on 23 June 2010 (CoW-a 2011a). This strategy, which aimed to boost the recycling of household garbage, was formally implemented in early October 2012. The principles of this plan are in line with the concept of a ZWS. To support the CoW's MSW-management plan, this study aims to predict quarterly YWG through the accurate prediction of MSW generation up to the target year of 2025 using only the twelve historical MSW data points from the year 2007 to 2018. Some studies used five years (Abbasi and El Hanandeh 2016; Liu et al. 2021) while some presented ten years (Ghinea et al. 2016; Mushtaq et al. 2020a, b) of prediction time. As there is no specific guideline, this study used seven years of forecasting period for the planning purpose. The term yard waste refers to decomposable waste materials such as grass, leaves, and small tree branches that have been trimmed during a growth phase.

Furthermore, the independent factors related to MSW generation require accurate forecasting which largely depends on the actual amount of MSW, which constitutes the motivation behind this study. Additionally, an accurate MSW generation forecast is required to quantify the potential amount of yard waste for the city to the assessment of energy recovered from MSW. To increase the prediction accuracy, unlike previous waste-prediction studies (AlSalem et al. 2018; Ayeleru et al. 2018), this study considers both socio-economic and climatic factors together in MSW generation prediction. At the same time, a correlation analysis approves the key independent factors relevant to the generation of the MSW for the city.

There are many data-intensive models, e.g. artificial neural network (ANN) (Ali and Ahmad 2019; Kontokosta et al. 2018), support vector (Meza et al. 2019; Niska and Serkkola 2018), and multiple linear regression (MLR) (Abdulredha et al. 2018; Golbaz et al. 2019), aimed at MSW prediction. However, due to high variability considered as the uncertainty (Singh 2019; Tsai et al. 2020) and an insufficient amount of historical data associated with MSW management and forecasting, grey forecasting models are more appropriate than data-intensive models approaches, as they are more effective at limiting forecasting error (Duman et al. 2019; Wang et al. 2018). As a result, this study uses the grey model, which is appropriate for forecasting future data with less prediction error (Liu et al. 2011). The grey model is a well-established forecasting model for predicting greytype data and dealing with uncertainty (Zhang et al. 2019). For example, Ren et al. (2013) and Ren (2018) used a grey model to predict the yield of biohydrogen under scanty data conditions and proved its superiority over the ANN model and support vector machine.

Most prediction methods based on time series involve moving averages and exponential smoothing (Gooijer \& Hyndman, 2006), neural networks (Tealab 2018), and grey models (Kayacan et al. 2010; Liu et al. 2011). The applicability of exponential smoothing and the moving-average method is limited to linear time series data. Excellent performance is shown by neural networks in both linear and nonlinear time-series data. However, for high accuracy, most neural networks require large quantities of data to train the system. In contrast, the grey model can be implemented in both linear and nonlinear data with uncertainty and does not require its sample to be as substantial for an accurate prediction (Liu et al. 2016).

There are two prominent types of prediction models commonly used to analyse time-series data in the method of the grey theory: $\mathrm{GM}(1,1)$ for single time-varying factors and 
$\mathrm{GM}(1, \mathrm{~N})$ for multiple time-varying factors (Kayacan et al. 2010). Grey forecasting includes the sequence forecasting, calamity forecasting, prediction of seasonal calamities, topological forecasting, and systematic forecasting ( $\mathrm{Lü}$ and $\mathrm{Lu}$ 2012). One of the grey theory's most significant features is the use of accumulated generation operation (AGO) to minimize data randomness (Zeng et al. 2020). The AGO approach efficiently eliminates noise by transforming random time series data into a monotonically increasing sequence, which can rapidly evaluate systematic regularity (Liu et al. 2016). Given the simplicity of the grey model and its potential for the prediction of time-series data, many researchers have begun to employ this model. It has been successfully used to study climate (Dengiz et al. 2019), energy (Li and Zhang 2019; Lu 2019), healthcare (Rahman et al. 2019), industrial technology and safety (Lü and Lu 2012), and petroleum exploration (Wang and Song 2019) among many subjects. Finally, the results obtained from the grey models are compared with the result obtained from the simple regression model as it has been applied in various waste prediction studies (Abdulredha et al. 2018; Golbaz et al. 2019).

The outcome of this study will support the efforts of urban planners, engineers, legislators, and researchersespecially those in the CoW-in sustainable planning for yard waste management in terms of budgeting, resource allocation, and estimating energy generation.

The rest of the paper is organized as follows: Section 2 gives the related materials and methods. Section 3 presents the results and discussions. Finally, Section 4 concludes this paper.

\section{Materials and Methods}

Three climatic factors with two conditions-temperature (average/maximum), humidity (average/maximum), and wind speed (average/maximum) —and eight socio-economic factors-population, number of households, number of labour force, employment number, household income, unemployment, income per employee, and GDP were considered as the independent factors for each quarter (winter, spring, summer, and fall) during the study period, as MSW generation largely depends on socio-economic and climatic factors (Kannangara et al. 2018; Vu et al. 2019). Quarterly waste data were used instead of annual waste data to ensure prediction accuracy, as MSW generation is not consistent throughout the year. Sections 2.2 and 2.3 discuss the available data on the independent factors and detail each of these factors, respectively. Key independent variables were screened out by the correlation analysis with respect to the target variable, MSW tonnage. Since the time length and sample size of the historical data on the independent factors and target variable were not identical, an identical time length and sample size of the independent variables' data are considered to the target variable, MSW generation.

The independent factors related to the target variable were used to develop the $\mathrm{GM}(1, \mathrm{~N})$ model, with individual factor modelling applying the GM $(1,1)$ model and single regression analysis (SRA). The grey models were constructed using MATLAB (v. 2017a). The accuracy of the models was then determined through five common statistical indices, including mean square error (MSE), mean absolute percentage error (MAPE), mean absolute error (MAE), root mean square error (RMSE), and correlation coefficient $\left(R^{2}\right)$ and one additional metric normalized-RMSE (NRMSE). The most accurate model was used to forecast the independent factors, and the GM $(1, \mathrm{~N})$ model was applied to predict MSW generation for the CoW. These values were then used to estimate the city's YWG. To calculate the amount of YWG, the percentage of YWG out of total MSW was measured using historical data. The future percentage of YWG was estimated for the target period using the GM (1, 1) model. Quarterly YWG was then evaluated by multiplying this percentage by the predicted quarterly MSW. Fig. 1 illustrates the methodology followed in this study.

\section{Study area}

The CoW is located in the south-central part of Manitoba, Canada, where the Red River meets the Assiniboine River, as shown in Electronic Supplementary Material (ESM) (Fig. S1). It comprises Manitoba's provincial capital as well as its surrounding municipalities, towns, and cities. Due to its flat topography, clay soils, and heavy snowfall, the CoW is subjected to yearly flooding (CoW-b 2011b). The city covers an area of $464.08 \mathrm{~km}^{2}$ with a population density of 1,430 persons per km² (Statistics Canada 2011).

The CoW's position in the Canadian Prairies gives it a continental tropical climate with very cold winters. Summers have a mean high temperature of $25.9^{\circ} \mathrm{C}$ and a mean low of $13.5^{\circ} \mathrm{C}$ (Weather Atlas 2020). Winter is the coldest and driest season of the year with the temperature ranging from $-21.4^{\circ} \mathrm{C}$ to $-11.3^{\circ} \mathrm{C}$ in January (Weather Atlas 2020). Winnipeg is a regional economic hub. According to a report on the city's economic development, it has one of the most diversified economies in the world, with large commercial (15.2\%), manufacturing $(9.8 \%)$, education (7.7 $\%$ ), and healthcare and community support (15.2\%) sectors (Economic Development Winnipeg 2016). The CoW had an average population of 719,269 in 2007-though this is expected to rise to 809,800 by 2023 (CoW 2019; Statistics Canada 2016). From 2002 to 2015, the number of households in the CoW has increased from around 249,000 to around 291,900 — an increase of 17\% (CoW-b 2018b). 
Fig. 1 Framework for YWG prediction from an estimated amount of MSW for the CoW

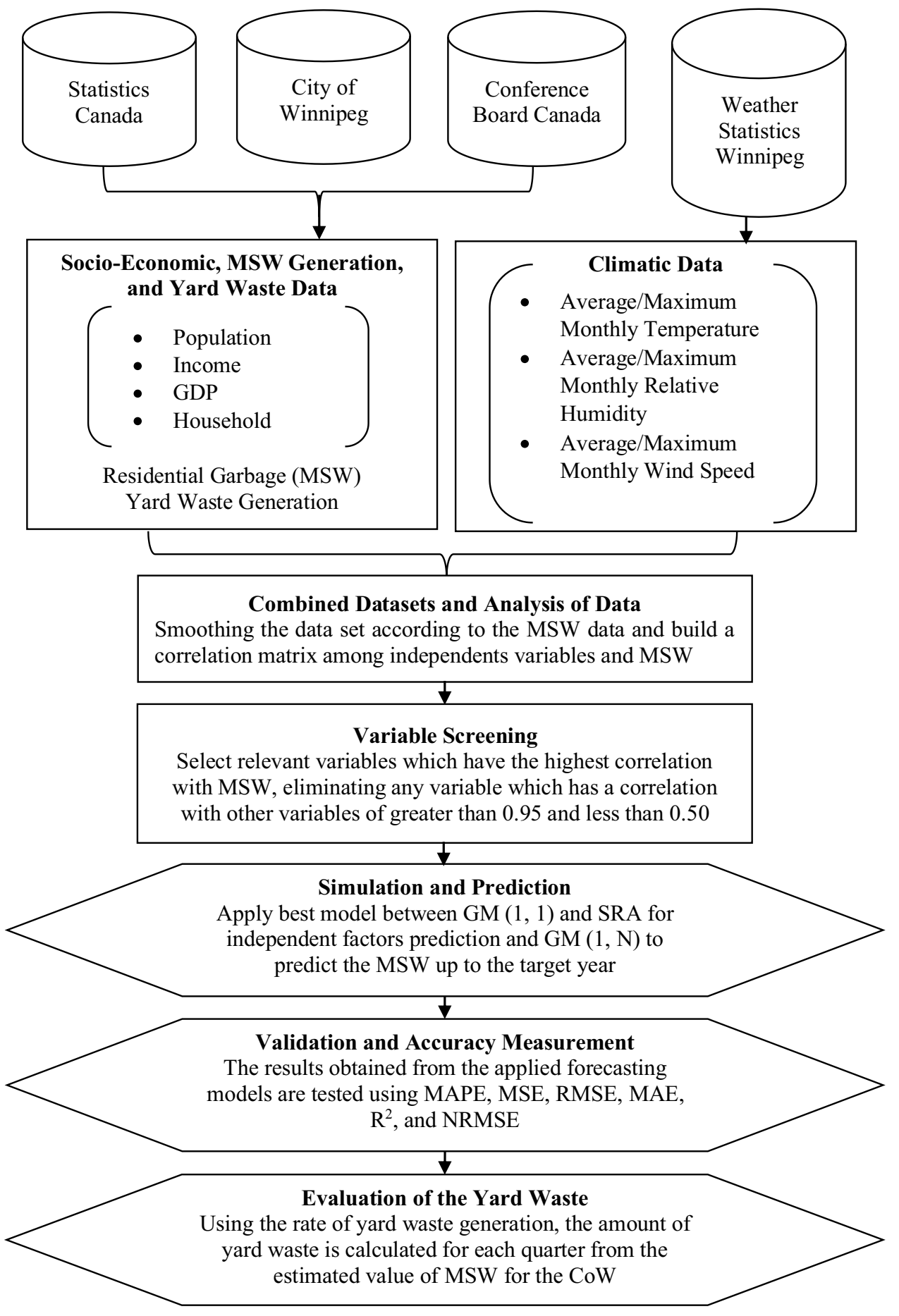

\section{Waste data availability}

While there are no available quarterly historical data on yard waste for the CoW, there are annual historical data on yard waste. However, there are both quarterly and annual historical data on MSW for the CoW. The descriptive statistics about the historical MSW data and the selected factors between 2007 and 2018 are presented in Table 1, and the quarterly historical data are displayed in ESM S1 (Table S1.1, Table S1.2, Table S1.3, and Table S1.4). Table 1 represents the four descriptive statistics: mean, standard deviation (St. Dev.), minimum (min.), maximum (max.), and coefficient of variation (CV) values of the target variable and the independent factors for four quarters. According to the table, the mean and the St. Dev. of the MSW generation in Q2 and Q3 are higher than that in Q1 
Table 1 Descriptive statistics of factors selected for the modelling of MSW generation

\begin{tabular}{|c|c|c|c|c|c|c|c|c|c|}
\hline \multicolumn{2}{|c|}{ Statistics } & \multicolumn{8}{|l|}{ Factors } \\
\hline & & MSW (tonne) & $\begin{array}{l}\text { Population } \\
\text { (number) }\end{array}$ & $\begin{array}{l}\text { Household } \\
\text { (number) }\end{array}$ & Income $(\$)$ & GDP (M \$, 2012) & $\begin{array}{l}\text { Wind } \\
\text { speed } \\
(\mathrm{Km} / \mathrm{h})\end{array}$ & Temperature $\left({ }^{\circ} \mathrm{C}\right)$ & Humidity (\%) \\
\hline \multirow[t]{5}{*}{ Q1 } & Mean & 39,003 & 762,191 & 275,549 & 31,330 & 37,352 & 18.381 & 10.470 & 76.871 \\
\hline & St. Dev. & 2,708 & 36,442 & 14,730 & 4,484 & 2,963 & 0.310 & 0.130 & 0.257 \\
\hline & Min. & 34,971 & 718,004 & 257,281 & 24,874 & 33,398 & 18.000 & 10.240 & 76.310 \\
\hline & Max. & 43,748 & 827,569 & 295,410 & 38,506 & 42,257 & 19.000 & 10.690 & 77.170 \\
\hline & $\mathrm{CV}$ & 0.069 & 0.048 & 0.053 & 0.143 & 0.079 & 0.017 & 0.013 & 0.003 \\
\hline \multirow[t]{5}{*}{ Q2 } & Mean & 56,643 & 764,648 & 275,549 & 31,657 & 37,641 & 16.582 & 16.946 & 92.761 \\
\hline & St. Dev. & 9,816 & 37,338 & 14,730 & 4,479 & 3,090 & 0.190 & 0.080 & 0.460 \\
\hline & Min. & 46,584 & 718,833 & 257,281 & 25,472 & 33,881 & 16.500 & 16.810 & 92.070 \\
\hline & Max. & 70,610 & 830,791 & 295,410 & 38,840 & 43,160 & 17.000 & 17.070 & 93.230 \\
\hline & $\mathrm{CV}$ & 0.173 & 0.049 & 0.053 & 0.141 & 0.082 & 0.012 & 0.005 & 0.005 \\
\hline \multirow[t]{5}{*}{ Q3 } & Mean & 55,042 & 767,141 & 275,549 & 31,996 & 37,875 & 31.310 & 23.080 & 90.370 \\
\hline & St. Dev. & 8,654 & 38,165 & 14,730 & 4,490 & 3,105 & 0.180 & 0.100 & 0.530 \\
\hline & Min. & 45,800 & 719,683 & 257,281 & 25,768 & 33,978 & 31.160 & 22.940 & 89.490 \\
\hline & Max. & 68,491 & 833,797 & 295,410 & 39,063 & 43,062 & 31.730 & 23.250 & 90.900 \\
\hline & $\mathrm{CV}$ & 0.157 & 0.050 & 0.053 & 0.140 & 0.082 & 0.006 & 0.004 & 0.006 \\
\hline \multirow[t]{5}{*}{ Q4 } & Mean & 46,895 & 769,671 & 275,549 & 32,269 & 38,053 & 29.620 & -1.070 & 88.270 \\
\hline & St. Dev. & 5,951 & 38,927 & 14,730 & 4,532 & 3,187 & 0.200 & 0.130 & 0.270 \\
\hline & Min. & 41,246 & 720,556 & 257,281 & 25,955 & 33,948 & 29.420 & -1.250 & 87.890 \\
\hline & Max. & 55,904 & 836,587 & 295,410 & 39,523 & 43,469 & 30.140 & -0.830 & 88.620 \\
\hline & $\mathrm{CV}$ & 0.127 & 0.051 & 0.053 & 0.140 & 0.084 & 0.007 & 0.124 & 0.003 \\
\hline
\end{tabular}

and Q4. Among the independent factors, the mean and the St. Dev. of population, income, and GDP are nearly the same across all four quarters, but they increase from the first quarter to the fourth quarter. The mean and the St. Dev. for the number of households are constant throughout each year. Since the climatic factors vary by season, their changes are random across the four quarters. Mean of the temperature and wind speed go higher in the third quarter and humidity goes higher in the second quarter. As seen in Table 1, the $\mathrm{CV}$ values of MSW are similar to those of Q2, Q3, and Q4, but are lower than those of MSW in Q1. Throughout the four quarters, the CVs of the independent components are more uniform for socio-economic components than for climatic elements. Humidity takes a uniform CV compared to wind speed and temperature.

The socio-economic data were collected from various open data sources related to the CoW (Conference Board of Canada 2020; CoW-a 2018a, b, 2016, 2019; Economic Development Winnipeg 2016, 2019; Statistics Canada 2011, 2016), and the climatic data were collected from the Weatherstats Winnipeg (Weatherstats 2020). The weather data were then transformed from monthly to quarterly on two levels: average and maximum. The minimum conditions for temperature, wind speed, and humidity have a negligible effect on YWG; as a result, they were not considered.
In the CoW, yard waste was collected in two ways: depot and self-haul collection and curbside collection. The total amount of yard waste corresponds to the summation of these collections. Figure 2 illustrates the annual yard waste information for the city from 2007 to 2018 . This figure indicates that YWG is gradually increasing over time. The figure also indicates that the CoW started yard waste collection in 2007, which was extended in 2010, and began to give it more attention in 2013. Additionally, yard waste prediction is important to quantify the amount of YWG beforehand to assess the energy recovery and to support the ZWS as well as to efficient MSW management.

\section{Socio-economic parameters selection}

The key criteria for choosing socio-economic factors were statistical significance and availability at the municipal level. After examining previous studies (Ayeleru et al. 2018; Kumar and Samadder 2017), this study initially considered eight socio-economic factors and six climatic factors $(\mathrm{Vu}$ et al. 2019) related to MSW generation, as established in Table 2. Ultimately, four major socio-economic factors (population, number of households, household income, and GDP) and four sets of three major climatic factors (one set per quarter) were selected for the study. To make these 
Fig. 2 Annual yard waste collection data for the $\mathrm{CoW}$ ( $\mathrm{CoW}$ 2020b)

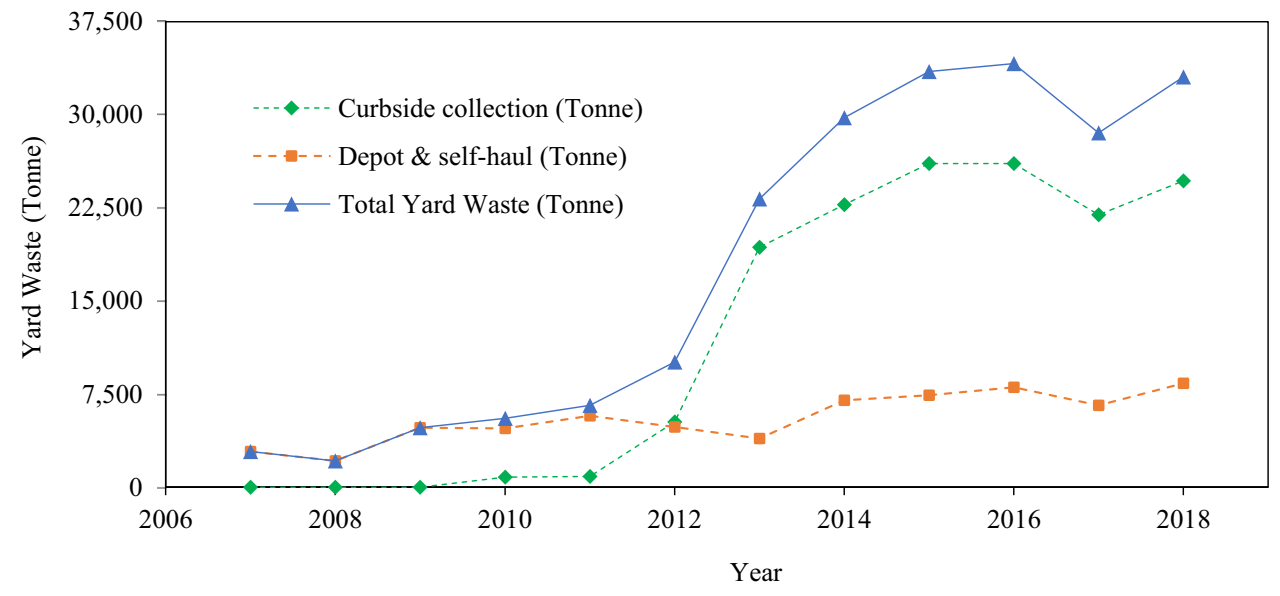

Table 2 Correlation matrix of dependent and independent factors for the first quarter (Q1)

\begin{tabular}{|c|c|c|c|c|c|c|c|c|c|c|c|c|c|c|c|c|}
\hline Factors & Q1 & $\mathrm{X} 1$ & $\mathrm{X} 2$ & $\mathrm{X} 3$ & $\mathrm{X} 4$ & $\mathrm{X} 5$ & X6 & $\mathrm{X} 7$ & $\mathrm{X} 8$ & $\mathrm{X} 9$ & $\mathrm{X} 10$ & $\mathrm{X} 11$ & $\mathrm{X} 12$ & $\mathrm{X} 13$ & $\mathrm{X} 14$ & $\mathrm{X} 15$ \\
\hline MSW (tonne) & $\mathrm{X} 1$ & 1.00 & & & & & & & & & & & & & & \\
\hline Population (number) & $\mathrm{X} 2$ & -0.65 & 1.00 & & & & & & & & & & & & & \\
\hline Household (number) & $\mathrm{X} 3$ & -0.74 & 0.95 & 1.00 & & & & & & & & & & & & \\
\hline Labour force & $\mathrm{X} 4$ & -0.64 & 0.98 & 0.95 & 1.00 & & & & & & & & & & & \\
\hline Employment (number) & $\mathrm{X} 5$ & -0.65 & 0.97 & 0.95 & 0.99 & 1.00 & & & & & & & & & & \\
\hline Income (\$) & $\mathrm{X} 6$ & -0.69 & 0.99 & 0.97 & 0.99 & 0.98 & 1.00 & & & & & & & & & \\
\hline Unemployment (number) & $\mathrm{X} 7$ & -0.49 & 0.89 & 0.85 & 0.90 & 0.84 & 0.90 & 1.00 & & & & & & & & \\
\hline Income per Employee (\$) & $\mathrm{X} 8$ & -0.69 & 0.98 & 0.96 & 0.97 & 0.95 & 0.99 & 0.92 & 1.00 & & & & & & & \\
\hline GDP (M \$, 2012) & X9 & -0.67 & 0.99 & 0.96 & 0.99 & 0.98 & 1.00 & 0.89 & 0.98 & 1.00 & & & & & & \\
\hline Average wind speed $(\mathrm{Km} / \mathrm{h})$ & $\mathrm{X} 10$ & -0.54 & 0.80 & 0.79 & 0.79 & 0.80 & 0.81 & 0.68 & 0.82 & 0.80 & 1.00 & & & & & \\
\hline Average temperature $\left({ }^{\circ} \mathrm{C}\right)$ & $\mathrm{X} 11$ & -0.22 & 0.79 & 0.59 & 0.79 & 0.78 & 0.74 & 0.73 & 0.70 & 0.77 & 0.54 & 1.00 & & & & \\
\hline Average humidity (\%) & $\mathrm{X} 12$ & -0.69 & 0.87 & 0.86 & 0.88 & 0.86 & 0.90 & 0.84 & 0.93 & 0.89 & 0.73 & 0.66 & 1.00 & & & \\
\hline Maximum wind speed $(\mathrm{Km} / \mathrm{h})$ & $\mathrm{X} 13$ & -0.18 & 0.42 & 0.24 & 0.37 & 0.41 & 0.35 & 0.20 & 0.29 & 0.38 & & & & 1.00 & & \\
\hline Maximum temperature $\left({ }^{\circ} \mathrm{C}\right)$ & $\mathrm{X} 14$ & -0.48 & 0.87 & 0.85 & 0.89 & 0.89 & 0.87 & 0.77 & 0.84 & 0.88 & & & & 0.22 & 1.00 & \\
\hline Maximum humidity (\%) & $\mathrm{X} 15$ & -0.46 & 0.40 & 0.42 & 0.40 & 0.37 & 0.45 & 0.46 & 0.52 & 0.42 & & & & -0.41 & 0.36 & 1.00 \\
\hline
\end{tabular}

selections, correlation analysis was performed between the target variable - MSW - and the initial 14 independent factors. Significant correlations among the factors were established to limit multicollinearity between the inputs (Daoud 2018). Due to increased standard errors, multicollinearity has statistical consequences, such as making an independent variable statistically insignificant. It makes the model difficult to comprehend and introduces an overfitting issue. To avoid this difficulty, highly related sets of parameters with correlation coefficients greater than absolute 0.95 were excluded (Abdoli et al. 2011). The correlation matrix for the first quarter is displayed in Table 2. The correlation matrices for the other three quarters are presented in ESM S3 (Table S3.1, Table S3.2, and Table S3.3).

These coefficients indicate the existence of collinearity between the independent factors and also represent a measure of the linear association between two variables. To validate the calculated values of the correlation coefficients, $R$, they were compared with the critical Pearson correlation coefficients, $R_{\text {Crit }}$ (Sousa et al. 2007) which is used to determine the linear correlation between two data sets. It can be calculated using the ratio of two variables' covariances to the product of their standard deviations. As a result, $R_{C r i t}$ is effectively a normalized measurement of covariances, with the result always lying between -1 and 1 . If the absolute value of a correlation coefficient exceeds the critical Pearson value, then the correlation coefficient is valid. $R_{C r i t}$ was calculated using the following equation:

$R_{c r i t}=\frac{t_{c r i t}}{\sqrt{D F+t_{c r i t}^{2}}}$

where $D F$ stands for degrees of freedom, which are the number of independent values that can vary in a statistical analysis without violating any constraints. For the n sample of 
observations and $\mathrm{k}$ number of grouped variables, the DF can be calculated as $D F=n-k$. The term, $t_{c r i t}$ refers to the "cutoff point' on the t-distribution which may be found in the t-distribution table. In this study, the total number of observations was 12 for each quarter and the number of grouped variables was two; hence, the degrees of freedom (12-2) were 10. Simultaneously, at 0.05 level of significance (twotailed test), $t_{C r i t}$ was 2.228 , resulting in $R_{\text {Crit }}$ equal to 0.576 .

According to Table 2, the socio-economic factors are strongly correlated with the climatic factors in their relation to the target variable, MSW. The following five socioeconomic factors-labour force, employment, household income, unemployment, and income per employee-can be considered by only one factor, household income, which has a strong correlation with MSW. Climatic factors showed a little significant effect on MSW generation but they are more responsible for YWG. This study selected three climatic factors-average wind speed, average humidity, and maximum temperature-for the first quarter based on a strong correlation with the MSW and among themselves. Following this way, a set of four socio-economic factors and three climatic factors are selected for the other three quarters.

\section{Grey theory}

This study utilizes the two basic grey models for individual factors and multivariable MSW prediction. The following subsections detail the models' solution procedures.

\section{GM $(1,1)$ Prediction Model}

The basic principles and modelling mechanism of GM (1, 1) is as follows (Liu et al. 2016):

Step 1. For $n$ samples, the original time sequence, $X^{(0)}$, is given as:

$$
X^{(0)}=\left[x^{(0)}(1), x^{(0)}(2), \ldots, x^{(0)}(n)\right] \quad n \geq 4
$$

To reduce the noise and disorderliness of the raw data, the AGO is applied to a new series, $X^{(1)}=\left[x^{(1)}(1), x^{(1)}(2), \ldots\right.$ ,$\left.x^{(1)}(n)\right]$, where $x^{(1)}$ is obtained as follows:

$x^{(1)}(k)=\sum_{i=1}^{k} x^{(0)}(i), \quad k=1,2,3, \ldots, n$

The generated mean sequence, $Z^{(1)}=\left[z^{(1)}(1), z^{(1)}(2), \ldots, z\right.$ $\left.{ }^{(1)}(n)\right]$ of $X^{(1)}$ is as follows:

$$
z^{(1)}(k)=\alpha x^{(1)}(k)+(1-\alpha) x^{(1)}(k-1), \quad k=2,3, \ldots, n
$$

Here, $\alpha$ is called the positioned coefficient of the interval grey number. The value of $\alpha$ is generally set as 0.5 for the generation of mean sequence; but, its value can be varied in the range of $[0,1]$.

Step 2. The first-order grey differential equation can be constructed as follows:

$x^{(0)}(k)+a z^{(1)}(k)=b$

The mean sequence generating equation of Eq. (5) is called the differential equation:

$\frac{d x^{(1)}}{d t}+a x^{(1)}=b$

where $a$ and $b$ are called the development and control coefficients, respectively. These coefficients can be obtained using the least-squares estimation method as follows:

$\hat{a}=\left[\begin{array}{l}a \\ b\end{array}\right]=\left[B^{T} B\right]^{-1} B^{T} Y$

Where, $B=\left[\begin{array}{cc}-z^{(1)}(2) & 1 \\ -z^{(1)}(3) & 1 \\ \vdots & \vdots \\ -z^{(1)}(n) & 1\end{array}\right]$, and $Y=\left[x^{(0)}(2) x^{(0)}(3), \ldots x^{(0)}(n)\right]^{T}$

Step 3. The grey prediction equation can be described as follows:

$\hat{x}^{(1)}(k)=\left[x^{(0)}(1)-\frac{b}{a}\right] e^{-a(k-1)}+\frac{b}{a}$

where $\hat{x}^{(1)}(k)$ indicates the prediction of $x^{(1)}(k)$ at time point $k$ and the initial condition, $x^{(1)}(1)=x^{(0)}(1)$. The inverse AGO (IAGO) sequence can be obtained as follows:

$\hat{x}^{(0)}(k)=\hat{x}^{(1)}(k)-\hat{x}^{(1)}(k-1), \quad k=2,3, \ldots, n$

\section{GM $(1, N)$ Prediction Model}

The multivariable grey forecasting model, represented by GM $(1, N)$, consists of a dependent variable sequence (system characteristic sequence) and ( $\mathrm{N}-1)$ independent variable sequences (related factor sequences). The basic modelling methods of the GM $(1, \mathrm{~N})$ model (Ren 2018; Ren et al. 2013) are as follows:

Step 1. Assume that there are $N$ variables denoted by $X_{i}$, where $(1,2,3, \ldots \ldots, N)$ and each variable have $n$ number of initial sequences. Let the original sequence of the variables be $X_{i}^{(0)}$.

$$
X_{i}^{(0)}=\left[X_{i}^{(0)}(1), X_{i}^{(0)}(2), \ldots, X_{i}^{(0)}(n)\right] \quad(i=1,2,3, \ldots, N)
$$


Applying the AGO to convert the original data into a new series, $X_{i}^{(1)}=\left[X_{i}^{(1)}(1), X_{i}^{(1)}(2), \ldots, X_{i}^{(1)}(n)\right] \quad(i=1,2, \ldots, N)$, where $X_{i}^{(1)}$ can be obtained as follows:

$X_{i}^{(1)}(k)=\sum_{j=1}^{k} X_{i}^{(0)}(j), \quad k=1,2,3, \ldots, n$

The generated mean sequence $Z_{1}^{(1)}=\left[Z_{1}^{(1)}(2), Z_{1}^{(1)}(3), \ldots, Z_{1}^{(1)}(n)\right]$ of $X_{1}^{(1)}$ can be calculated as follows:

$Z_{1}^{(1)}(k)=\alpha x_{1}^{(1)}(k)+(1-\alpha) x_{1}^{(1)}(k-1), \quad k=2,3, \ldots, n$

Step 2. The first-order grey differential equation can be constructed as follows:

$X_{1}^{(0)}(k)+a Z_{1}^{(1)}(k)=\sum_{i=2}^{N} b_{i} X_{i}^{(1)}(k)$

The image equation of Eq. (13) is:

$\frac{d X_{1}^{(1)}(k)}{d t}+a X_{1}^{(1)}(k)=\sum_{i=2}^{N} b_{i} X_{i}^{(1)}(k)$

where the coefficients $a$ and $b_{i}$ can be calculated as follows:

For, $n \leq N+1$,

$\hat{P}=\left(a, b_{2}, b_{3}, \ldots, b_{N}\right)^{T}=B^{-1} Y$

For, $n>N+1$,

$\hat{P}=\left(a, b_{2}, b_{3}, \ldots, b_{N}\right)^{T}=\left[B^{T} B\right]^{-1} B^{T} Y$

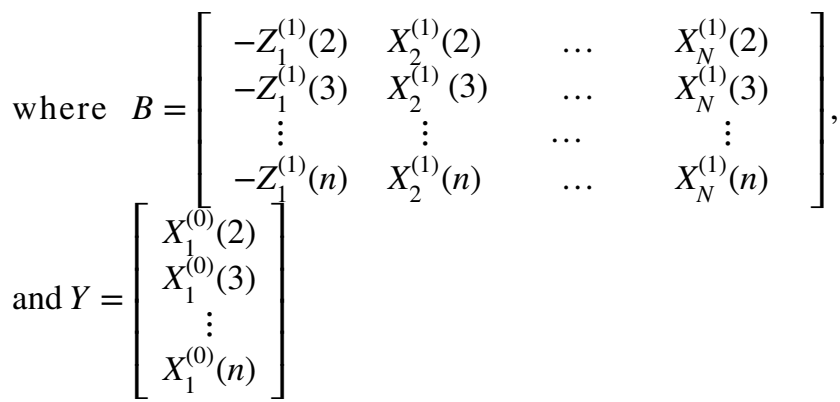

Step 3. Using $a$ and $b_{i}$, the grey prediction equation can be expressed as follows:

$\hat{X}_{1}^{(1)}(k+1)=\left[X_{1}^{(1)}(1)-\frac{1}{a} \sum_{i=2}^{N} b_{i} X_{i}^{(1)}(k+1)\right] e^{-a k}+\frac{1}{a} \sum_{i=2}^{N} b_{i} X_{i}^{(1)}(k+1)$

where $\hat{X}_{1}^{(1)}(k+1)$ indicates the prediction of $X_{1}^{(1)}(k)$ at time point $k$ with the initial condition, $X_{1}^{(1)}(1)=X_{1}^{(0)}(1)$. The IAGO sequence can be obtained as follows:
$\hat{X}_{1}^{(0)}(k+1)=\hat{X}_{1}^{(1)}(k+1)-\hat{X}_{1}^{(1)}(k), \quad k=2,3, \ldots, n$

\section{Metrics of Forecasting Error Analysis}

Performance analysis is important for assessing the accuracy of forecasting models. The model's predictive performance was assessed using five metrics that are common in studies of waste prediction (Kumar and Samadder 2017; Younes et al. 2015). These metrics-MAPE, MAE, MSE, RMSE, and $R^{2}$-are specified below.

$M A P E=\frac{1}{n} \times \sum_{i=1}^{n}\left|\frac{Y_{i}-\hat{Y}_{i}}{Y_{i}}\right| \times 100$

$\mathrm{MAE}=\frac{1}{n} \sum_{i=1}^{n}\left|Y_{i}-\hat{Y}_{i}\right|$

$M S E=\frac{1}{n} \times \sum_{i=1}^{n}\left(\hat{Y}_{i}-Y_{i}\right)^{2}$

$R M S E=\sqrt{\frac{1}{n} \times \sum_{i=1}^{n}\left(\hat{Y}_{i}-Y_{i}\right)^{2}}$

$R^{2}=1-\frac{\sum_{i=1}^{n}\left(\hat{Y}_{i}-Y_{i}\right)^{2}}{\sum_{i=1}^{n}\left(Y_{i}-\bar{Y}_{i}\right)^{2}}$

where

$n \quad$ Number of raw data points

$Y_{i} \quad$ The actual mass of MSW

$\hat{Y}_{i} \quad$ Predicted mass of MSW

$\bar{Y}_{i} \quad$ The mean of actual MSW

In these formulations, the first four metrics require a value close to zero, while the last metric requires a value close to one. Besides these five metrics, St. Dev. (observed data)-based NRMSE is also used to evaluate and compare the prediction accuracy of the GM $(1, \mathrm{~N})$ model. Among the five error metrics, the MAPE is the most popular goodnessof-fit indicator for forecasting problems (Islam et al. 2021). Following the Lewis scale (Javed et al. 2020), as shown below, a MAPE of less than $20 \%$ is indicative of a reliable forecast. However, the forecasting accuracy of the prediction models used in this study is evaluated with the help of the aforementioned five metrics simultaneously. 
$\operatorname{MAPE}(\%)=\left\{\begin{array}{cc}<10 & \text { Highly accurate forecast } \\ 10 \sim 20 & \text { Good forecast } \\ 20 \sim 50 & \text { Reasonable forecast } \\ >50 & \text { Inaccurate forecast }\end{array}\right.$

\section{Results and Discussion}

\section{Independent factors prediction}

The details of the comparative analysis-including the simulation errors-of independent factors are presented in ESM
S2 (Table S2.1-Table S2.6). To avoid unnecessary repetition and ensure a clear understanding of the forecasting accuracy of the GM $(1,1)$ model over SRA, Fig. 3 only demonstrates the forecasting error of the 'population'. Three types of errors have been measured for each factor: in a sample ( 9 data points), out of a sample (3 data points), and overall (12 data points) for each forecasting error metric. According to Fig. 3 and the tables displayed in ESM S2, the GM $(1,1)$ model outperforms the SRA model across all of the factors.

For climatic factors, such as humidity, temperature, and wind speed, the two models' prediction accuracy is very closer to the socio-economic factors. In some quarters, the climatic factors have small $R^{2}$ values for both predictive
Fig. 3 Forecasting error in prediction of the population for $\operatorname{GM}(1,1)$ model and SRA [A-E]
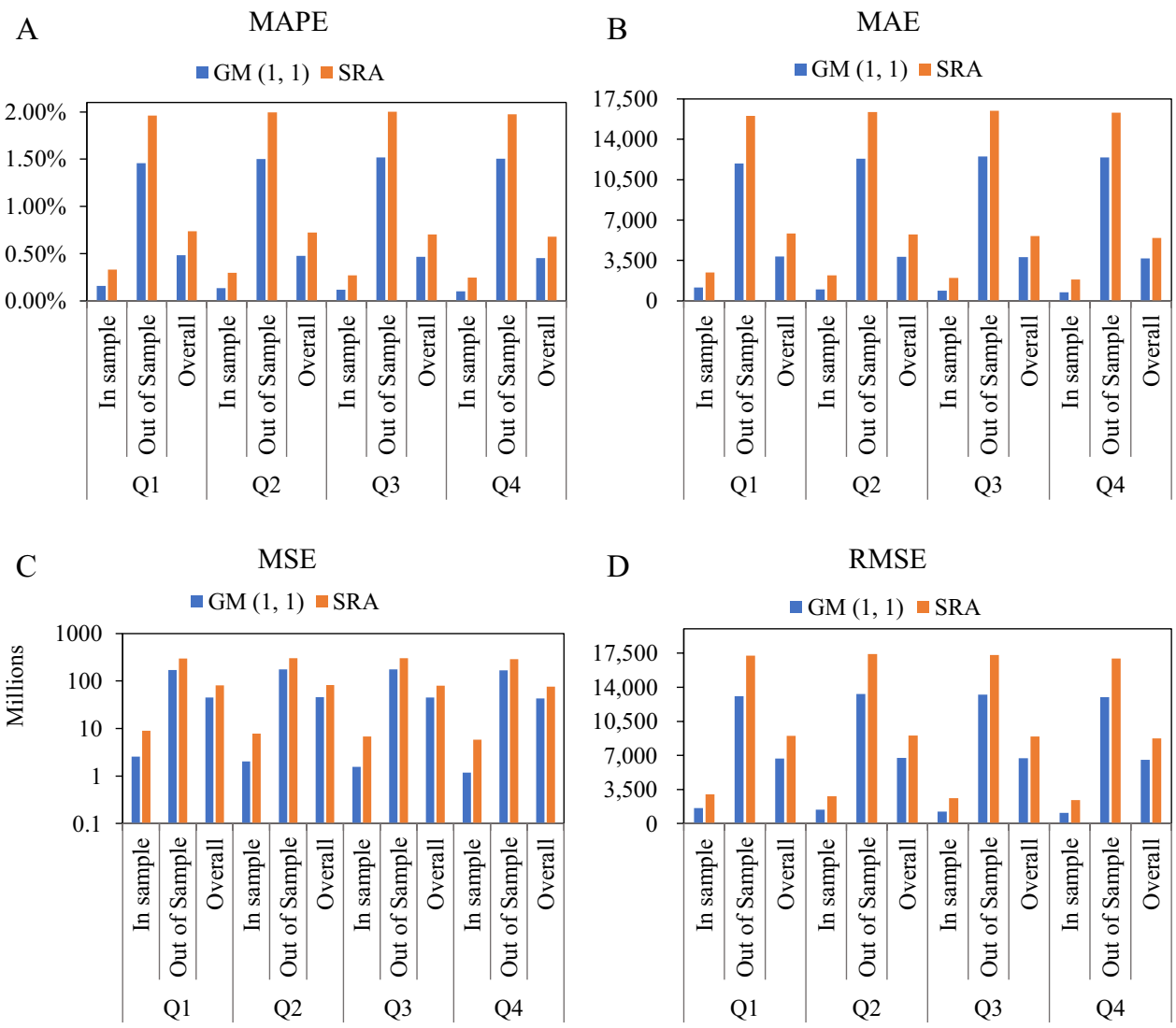

$\mathrm{D}$

RMSE

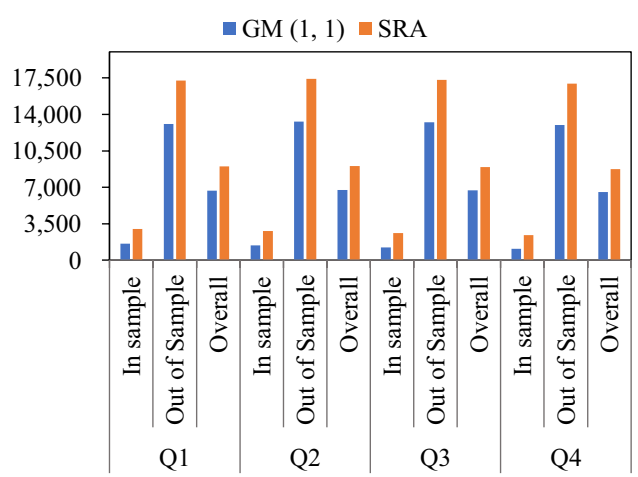

R2

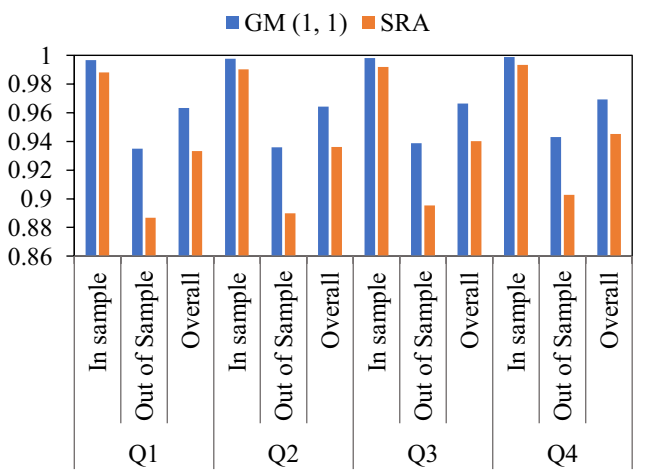


models. Additionally, in some quarters the out-of-sample error is higher than the in-sample error, and in some cases, both errors are higher. All of these phenomena are somewhat statistically insignificant and one of the reasons behind these errors could be the bias and variance errors of regression and prediction model. The bias-variance trade-off can be used to address these issues more accurately. However, examining the overall accuracy of the five-metrics described in ESM $\mathrm{S} 2$, it is clear that the $\mathrm{GM}(1,1)$ model generates a more accurate prediction for the climatic factors than the SRA model.

The prediction accuracy for the 'household' factor was the same across all four quarters, as the number of households in the CoW was constant throughout each year. This analysis supports the GM $(1,1)$ model's applicability in the prediction of individual factors of MSW generation. Based on this error analysis, the GM $(1,1)$ model was selected to predict the independent factors over the next seven years, from 2019 to 2025, which was then used to forecast MSW generation up to the target period. And finally, the predicted amount of MSW is used to estimate the YWG for the city up to the target period. This process will, theoretically, continue in five-year increments throughout the course of the CoW's master-plan target year-2045. This stepwise prediction will help the city to examine its seasonal variation in waste generation. By examining the historical data, it is clear that waste generation is not consistent throughout the year; as a result, quarterly MSW prediction is warranted. The forecasted results for each factor obtained from the GM (1, 1) model are shown in Table 3.

Table 3 indicates that the predicted results of the target variable and the independent factors are increasing over time. Among the indecent factors, the four selected socioeconomic factors are highly increasing as their historical data were increasing in trend. However, the changes for the climatic factors are reasonably small for their less variability in each quarter. These results for the independent factors constitute the input for the GM $(1, \mathrm{~N})$ model for the MSW prediction up to the year 2025. After computing the MSW
Table 3 Forecasted results for each independent factor for the entire four quarters

\begin{tabular}{|c|c|c|c|c|c|c|c|c|}
\hline \multirow[t]{2}{*}{ Quarter } & \multirow[t]{2}{*}{ Factors } & \multicolumn{7}{|l|}{ Year } \\
\hline & & 2019 & 2020 & 2021 & 2022 & 2023 & 2024 & 2025 \\
\hline \multirow[t]{7}{*}{ Q1 } & Population (number) & 831,678 & 843,260 & 855,003 & 866,909 & 878,981 & 891,221 & 903,631 \\
\hline & Household (number) & 302,722 & 307,254 & 311,853 & 316,522 & 321,260 & 326,069 & 330,950 \\
\hline & Income (\$) & 40,126 & 41,742 & 43,423 & 45,171 & 46,990 & 48,882 & 50,850 \\
\hline & GDP (millions \$, 2012) & 43,044 & 44,023 & 45,023 & 46,047 & 47,094 & 48,164 & 49,260 \\
\hline & Wind speed $(\mathrm{km} / \mathrm{h})$ & 18.82 & 18.89 & 18.96 & 19.03 & 19.10 & 19.18 & 19.25 \\
\hline & Temperature $\left({ }^{\circ} \mathrm{C}\right)$ & 10.70 & 10.74 & 10.78 & 10.81 & 10.85 & 10.89 & 10.93 \\
\hline & Humidity (\%) & 77.25 & 77.31 & 77.36 & 77.42 & 77.47 & 77.53 & 77.58 \\
\hline \multirow[t]{7}{*}{ Q2 } & Population (number) & 835,834 & 847,703 & 859,741 & 871,950 & 884,332 & 896,890 & 909,626 \\
\hline & Household (number) & 302,722 & 307,254 & 311,853 & 316,522 & 321,260 & 326,069 & 330,950 \\
\hline & Income (\$) & 40,514 & 42,146 & 43,844 & 45,611 & 47,449 & 49,361 & 51,350 \\
\hline & GDP (millions \$, 2012) & 43,665 & 44,713 & 45,786 & 46,885 & 48,010 & 49,163 & 50,343 \\
\hline & Wind speed $(\mathrm{km} / \mathrm{h})$ & 16.68 & 16.71 & 16.73 & 16.75 & 16.78 & 16.80 & 16.82 \\
\hline & Temperature $\left({ }^{\circ} \mathrm{C}\right)$ & 17.07 & 17.10 & 17.12 & 17.14 & 17.16 & 17.18 & 17.20 \\
\hline & Humidity (\%) & 93.53 & 93.65 & 93.77 & 93.89 & 94.01 & 94.13 & 94.25 \\
\hline \multirow[t]{7}{*}{ Q3 } & Population (number) & 839,880 & 852,010 & 864,315 & 876,798 & 889,461 & 902,307 & 915,339 \\
\hline & Household (number) & 302,722 & 307,254 & 311,853 & 316,522 & 321,260 & 326,069 & 330,950 \\
\hline & Income $(\$)$ & 40,834 & 42,458 & 44,148 & 45,905 & 47,731 & 49,630 & 51,605 \\
\hline & GDP (millions \$, 2012) & 43,846 & 44,880 & 45,939 & 47,022 & 48,132 & 49,267 & 50,429 \\
\hline & Wind speed $(\mathrm{km} / \mathrm{h})$ & 31.59 & 31.63 & 31.68 & 31.73 & 31.78 & 31.82 & 31.87 \\
\hline & Temperature $\left({ }^{\circ} \mathrm{C}\right)$ & 23.21 & 23.23 & 23.25 & 23.28 & 23.30 & 23.32 & 23.34 \\
\hline & Humidity (\%) & 91.23 & 91.36 & 91.50 & 91.63 & 91.76 & 91.89 & 92.03 \\
\hline \multirow[t]{7}{*}{ Q4 } & Population (number) & 843,815 & 856,178 & 868,723 & 881,451 & 894,366 & 907,470 & 920,765 \\
\hline & Household (number) & 302,722 & 307,254 & 311,853 & 316,522 & 321,260 & 326,069 & 330,950 \\
\hline & Income (\$) & 41,208 & 42,852 & 44,561 & 46,339 & 48,187 & 50,109 & 52,108 \\
\hline & GDP (millions \$, 2012) & 44,209 & 45,276 & 46,370 & 47,489 & 48,635 & 49,810 & 51,012 \\
\hline & Wind speed $(\mathrm{km} / \mathrm{h})$ & 29.89 & 29.94 & 29.98 & 30.02 & 30.07 & 30.11 & 30.15 \\
\hline & Temperature $\left({ }^{\circ} \mathrm{C}\right)$ & -0.94 & -0.93 & -0.91 & -0.89 & -0.87 & -0.86 & -0.84 \\
\hline & Humidity (\%) & 88.51 & 88.54 & 88.58 & 88.61 & 88.64 & 88.68 & 88.71 \\
\hline
\end{tabular}


generation, the final prediction of YWG is measured from the predicted amount of the MSW for the city.

\section{MSW prediction}

Since the main MSW-prediction model in this study is a multivariable prediction problem with limited historical data over a 12-year period, the multifactor MSW-forecasting model is solved using the GM $(1, \mathrm{~N})$ model, which is effective for working with limited data. The forecasted result is illustrated in Fig. 4, which shows a downward trend in annual MSW generation in the CoW. The decline is due to the decline in the historical data and the negative correlation between the independent factors and the target variable. Furthermore, CoW authorities have already undertaken efforts to enhance their waste management procedures. As a result of these efforts, including residential food waste collection pilot project, automated recycling collection, composting, landfill monitoring, the decline in MSW generation-though small in the first quarter-is significant. After the first quarter, gardening works and a variety of outdoor activities arise. In the summer, more food waste is generated, which explains why the waste generation varies with the first quarter with the remaining three quarters.

The accuracy of the simulation is displayed in ESM S4 (Table S4.1). The table represents three types of errors of the $\operatorname{GM}(1, \mathrm{~N})$ model for each quarter: in a sample $(10$ data points), out of a sample (2 data points), and overall (12 data points). The NRMSE metric is applied to compare the quarterly predicted results when the $R^{2}$ value is lower and in the case where $R^{2}$ is always constant-one for two samples.

According to Table S4.1, MAPE and $R^{2}$ indicate an acceptable result for the multivariable prediction of MSW generation using the GM $(1, \mathrm{~N})$ model. According to the Lewis scale of prediction accuracy mentioned in Section 2.5, the in-sample and overall MAPE values for each quarter are below $10 \%$ which indicates a highly accurate forecast. At the same time, out-of-sample MAPE values for Q1 and Q3 are relatively greater the $\mathrm{Q} 2$ and $\mathrm{Q} 4$. The value of $R^{2}$ in the first quarter shows comparably small values than the other three quarters in MSW prediction. However, the NRMSE value of Q1 in three error categories indicates a significant prediction accuracy compared to the other three quarters. On the other hand, the MAE, MSE, and RMSE expressed relatively greater values for different ranges and higher variations in the historical data of the selected independent factors. Though the-out-of-sample error results are relatively higher than the in-sample and overall error results, analysing the overall error results displayed in the above table, for only twelve-point historical data sets, the GM $(1, \mathrm{~N})$ model can be used to predict the amount of MSW generation for the city precisely to each quarter. This accurately predicted result of the MSW generation is required for the precise estimation of the YWG for the city up to the target period.

\section{Yard waste prediction}

Figure 5(a) illustrates the pattern of YWG with the total MSW using the collected data. Though the trend is not linear, yard waste is increasing over time, while total MSW is declining. This decline can be attributed to the start of the CoW's master plan in 2012. The figure also represents that the rate of YWG is increasing over time.

The YWG predictions for each quarter are depicted in Fig. 5(b). The figure also represents the estimated percent of the YWG to the amount MSW up to the target period. While the figure shows an upward trend for the future percentage of the YWG, quarterly YWG indicates a decline throughout each year. This can be explained from Fig. 5 which indicates that the MSW generation is decreasing while the YWG is increasing over time.

According to Fig. 5(b), the first quarter (Q1) demonstrates a nearly constant YWG trend, as almost no yard activities are expected during the winter, which largely falls within this quarter. Besides, it was found that the predicted result
Fig. 4 Prediction of the MSW up to the year 2025

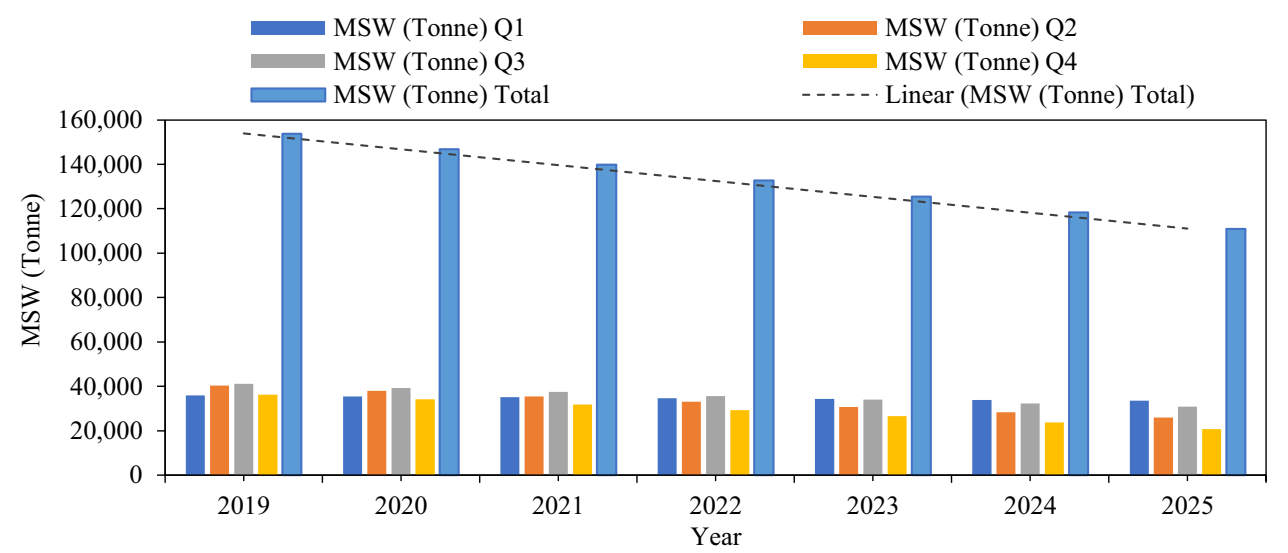


Fig. 5 Rate of YWG to the total amount of MSW and quarterly predicted YWG for the CoW. (a) Rate of YWG to the total amount of MSW, (b) Illustration of the quarterly predicted YWG

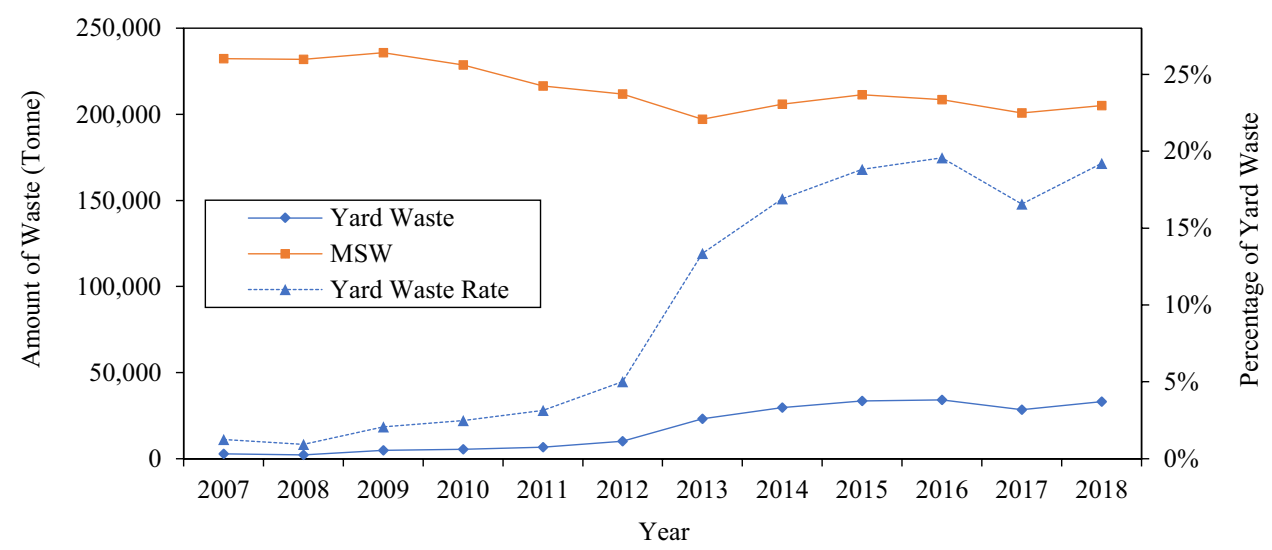

(a)

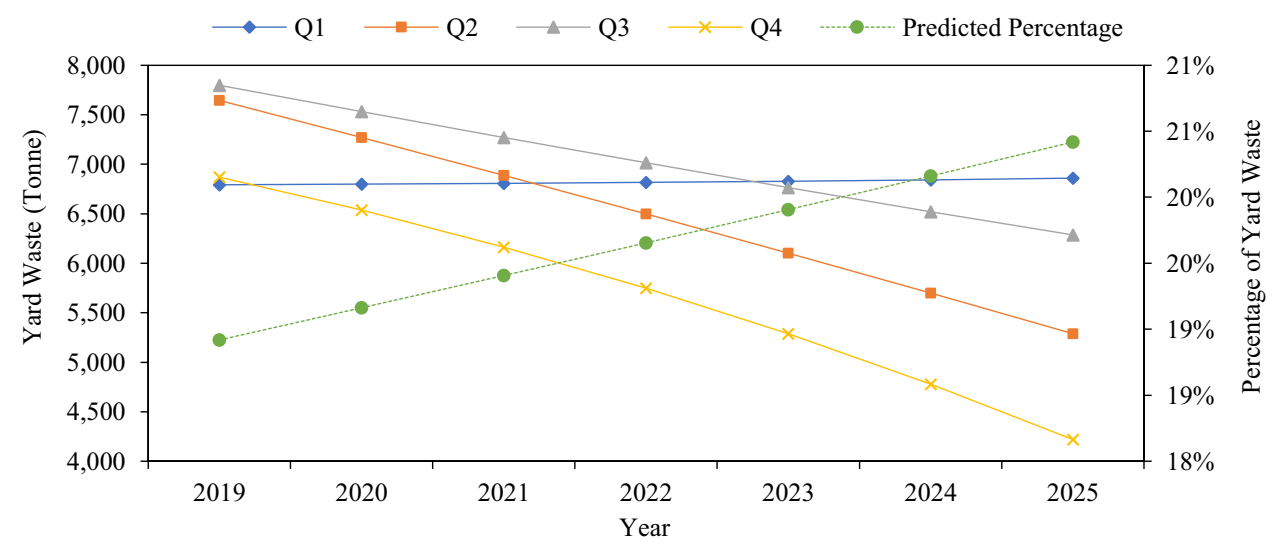

(b) of the first quarter's MSW generation is relatively constant throughout the target period. For the other three quarters, the predicted result of the MSW generation is falling sharply up to the target period which is why the YWG is also shown a declining trend. This predicted result of YWG obtained from the forecasted MSW generation indicates that if the city maintains its current speed of efforts to the waste management in constant up to the target period then the city will reach this predicted stage of waste generation.

Finally, this study is aligned with the research of waste prediction-related studies where socio-economic factors are considered as the key influential variables for MSW generation (Al-Salem et al. 2018; Ferronato et al. 2020; Kannangara et al. 2018). Additionally, since the primary objective of this study is to predict the YWG from the forecasted MSW and the climatic factors are largely related to YWG, this research also considers climatic factors as influential factors (Vu et al. 2019). A few studies appear in the literature where both socio-economic and climatic factors are considered simultaneously. One of the significant aspects of this study is the application of seven independent factors concurrently to measure the MSW generation and YWG for the CoW. Furthermore, recent literature on the COVID-19 pandemic suggested that Canadian waste generation characteristics have been impacted (Richter et al. 2021a, b; Vu et al. 2021). Thus, a study focusing on the effects of COVID on CoW waste management is recommended.

\section{Conclusions}

In SWM systems, accurate prediction of the MSW generation plays an important role in the development of effective steps towards sustainable economic development through a ZWS. This study presents a grey theorybased YWG-prediction method that utilizes the predicted quarterly MSW for the CoW. This study aimed to support the CoW's master plan to achieve a ZWS by 2045 . Accurate YWG predictions can simplify efforts to estimate energy recovery through composting. Unlike previous waste-prediction research, this study considered the potential influence of both socio-economic and climatic factors. This study also conducted correlation analysis to identify the key influences among the considered factors. Additionally, it estimated the individual factors throughout the target period using the GM $(1,1)$ model, 
which proved to be superior to the SRA model. It produced individual-factor predictions with MAPE values of $0.26 \%-8.32 \%$ for the in-sample data. The GM $(1, \mathrm{~N})$ model was also used to model the multivariable MSW prediction using the socio-economic and climatic factors. This generated overall MAPE values of 5.64\%-7.54\% with suitable results for other error metrics. The results of this study demonstrate that the grey models can reliably predict both MSW and YWG. The most significant advantage of the grey method is that-even with a very limited number of samples-it provides precise predictions. Therefore, the GM $(1, N)$ model has effectively simulated waste prediction with a lower computational cost in cases of poor information.

The findings of this study must be seen in light of its limitations. One of the potential limitations to the generalization of these results is the decline in MSW in contrast to the values of the independent factors, several of which showed negative correlations with MSW. This could have led to a biased prediction showing undesirable outcomes to the target variables. In addition, this study directly implemented the basic grey models in waste prediction without considering the optimal design of its background parameters. A robust design of the grey models' background parameters can generate a more precise prediction. Finally, the current system of waste projection can be extended across Canada because the socio-economic parameter values can be established consistently utilizing census data available to all municipalities in Canada.

Supplementary Information The online version contains supplementary material available at https://doi.org/10.1007/s11356-022-19178-y.

Acknowledgment The authors are grateful to the prestigious scholarship, Queen Elizabeth II Diamond Jubilee Scholarship, and the Visiting Graduate Research Program of the University of Regina, Canada which allows performing this study.

Authors Contributions Md Rakibul Islam contributed to the conceptualization, methodology, formal analysis, investigation, data curation, result visualization and preparing initial draft. Golam Kabir and Kelvin Tsun Wai $\mathrm{Ng}$ contributed to the conceptualization, data curation, model validation, result visualization, drafting the final document, and project supervision. Syed Mithun Ali contributed to the model validation, result visualization, and drafting the final document.

Availability of data and materials The datasets used and/or analysed are available from the corresponding author on reasonable request.

\section{Declarations}

Ethics approval We declare that this manuscript is original, has not been published before, and is not currently being considered for publication elsewhere.
Consent to participate Not applicable.

Consent for publication I, the undersigned, give my consent for the publication of identifiable details, which can include data, figures, and tables, and details within the text to be published in this article.

Competing Interests The authors declare that they have no competing interests.

\section{References}

Abbasi M, El Hanandeh A (2016) Forecasting municipal solid waste generation using artificial intelligence modelling approaches. Waste Manag 56:13-22. https://doi.org/10.1016/j.wasman.2016. 05.018

Abdoli MA, Falahnezhad M, Behboudian S (2011) Multivariate econometric approach for solid waste generation modeling: Impact of climate factors. Environ Eng Sci 28(9):627-633. https://doi.org/ 10.1089/ees.2010.0234

Abdulredha M, Al Khaddar R, Jordan D, Kot P, Abdulridha A, Hashim K (2018) Estimating solid waste generation by hospitality industry during major festivals: A quantification model based on multiple regression. Waste Manag 77:388-400. https://doi.org/10.1016/j. wasman.2018.04.025

Adamović VM, Antanasijević DZ, Ristić M, Perić-Grujić AA, \& Pocajt VV (2017). Prediction of municipal solid waste generation using artificial neural network approach enhanced by structural break analysis. In Environmental Science and Pollution Research (Vol. 24, Issue 1, pp. 299-311). https://doi.org/10.1007/ s11356-016-7767-x

Ali SA, Ahmad A (2019) Forecasting MSW generation using artificial neural network time series model: a study from metropolitan city. SN Appl Sci 1(11):1-16. https://doi.org/10.1007/ s42452-019-1382-7

Allen MP (1997) The problem of multicollinearity. In Understanding Regression Analysis. Springer, New York, pp 176-180. https:// doi.org/10.1007/978-0-585-25657-3 37

Allen C, Gokaldas V, Larracas A, Minot LA, Morin M, Tangri N et al (2012) The Road to Zero Waste: Successes and Lessons from around the World. Global Alliance for Incinerator Alternatives, Philippines https://www.no-burn.org/wp-content/uploads/On-theRoad-to-Zero-Waste.pdf. Accessed 2 Jan 2020

Al-Salem SM, Al-Nasser A, Al-Dhafeeri AT (2018) Multi-variable regression analysis for the solid waste generation in the State of Kuwait. Process Saf Environ Prot 119:172-180. https://doi.org/ 10.1016/j.psep.2018.07.017

Ayeleru OO, Okonta FN, Ntuli F (2018) Municipal solid waste generation and characterization in the City of Johannesburg: A pathway for the implementation of zero waste. Waste Manag 79:87-97. https://doi.org/10.1016/j.wasman.2018.07.026

Azadi S, Karimi-Jashni A (2016) Verifying the performance of artificial neural network and multiple linear regression in predicting the mean seasonal municipal solid waste generation rate: A case study of Fars province. Iran Waste Manag 48:14-23. https://doi. org/10.1016/j.wasman.2015.09.034

Boumanchar I, Chhiti Y, M'hamdi Alaoui FE, Sahibed-dine A, Bentiss F, Jama C, Bensitel M (2019) Municipal solid waste higher heating value prediction from ultimate analysis using multiple regression and genetic programming techniques. Waste Manag Res 37(6):578-589. https://doi.org/10.1177/0734242X18816797

Bruce N, Asha AZ, Ng KTW (2016) Analysis of solid waste management systems in Alberta and British Columbia using provincial 
comparison. Can J Civ Eng 43(4):351-360. https://doi.org/10. 1139/cjce-2015-0414

Chowdhury A, Vu HL, Ng KTW, Richter A, Bruce N (2017) An investigation on Ontario's non-hazardous municipal solid waste diversion using trend analysis. Can J Civ Eng 44(11):861-870. https:// doi.org/10.1139/cjce-2017-0168

Cocker J, Graham K (2019) Circular economy in Canada. In: Circular Economy: Global Perspective, Springer Singapore, Singapore, pp 87-122. https://doi.org/10.1007/978-981-15-1052-6_5

Conference Board of Canada. (2020). Metropolitan Forecastof Major Economic Factors Data Directory. https://www-conferenceboardca.libproxy.uregina.ca/e-data/browsedirectories.aspx $? d i d=26$. Accessed 2 Jan 2020

CoW-a. (2011a). Garbage and Recycling Master Plan - Public Engagement - Water and Waste - City of Winnipeg. https://winnipeg. $\mathrm{ca} /$ waterandwaste/publicengagement/g-and-r-master-plan/defau lt.stm\#tab-background. Accessed 2 Jan 2020

CoW-b. (2011b). Our Winnipeg: It's Our City, It's Our Plan, It's Our Time. https://www.winnipeg.ca/interhom/CityHall/OurWinnipeg/ pdf/OurWinnipeg.pdf. Accessed 2 Jan 2020

CoW (2016). City of Winnipeg Population, Housing and Economic Forecast Report. https://www.winnipeg.ca/finance/files/CoWPopulation-Housing-and-Economic-Forecast.pdf. Accessed 2 Jan 2020

CoW-a. (2018a). Recycling Reports I Open Data I City of Winnipeg. https://data.winnipeg.ca/Organizational-Support-Services/ Recycling-Reports/83vb-f9i3. Accessed 2 Jan 2020

CoW-b. (2018b). City of Winnipeg Population, Housing, And Economic Forecast. https://www.winnipeg.ca/finance/documents_ page.stm. Accessed 2 Jan 2020

CoW. (2019). City Of Winnipeg Population I Open Data I City of Winnipeg. https://data.winnipeg.ca/City-Planning/City-Of-WinnipegPopulation/mhuw-u7yg. Accessed 2 Jan 2020

CoW-a. (2020a). Garbage Reports I Open Data I City of Winnipeg. https://data.winnipeg.ca/Organizational-Support-Services/ Garbage-Reports/y6ne-5ub8. Accessed 2 Jan 2020

CoW-b. (2020b). Yard Waste Reports I Open Data I City of Winnipeg. https://data.winnipeg.ca/Organizational-Support-Services/YardWaste-Reports/n5fd-umxv

Daoud JI (2018) Multicollinearity and Regression Analysis. J Phys Conf Ser 949(1):12009. https://doi.org/10.1088/1742-6596/949/1/ 012009

De Gooijer JG, Hyndman RJ (2006) 25 Years of Time Series Forecasting. Int J Forecast 22(3):443-473. https://doi.org/10.1016/j.ijfor ecast.2006.01.001

Deng J-L (1982) Control problems of grey systems. Syst Control Lett I(5):288-294. https://doi.org/10.1016/S0167-6911(82)80025-X

Dengiz AÖ, Atalay KD, Dengiz O (2019) Grey Forecasting Model for CO2 Emissions of Developed Countries A. Proc Int Symp Prod Res 2018(1):604-611. https://doi.org/10.1007/978-3-319-92267-6

Ding Z, Shi M, Lu C, Wu Z, Chong D, Gong W (2019) Predicting Renovation Waste Generation Based on Grey System Theory: A Case Study of Shenzhen. Sustainability 11(16):4326. https://doi. org/10.3390/su11164326

Duman GM, Kongar E, Gupta SM (2019) Estimation of electronic waste using optimized multivariate grey models. Waste Manag 95:241-249. https://doi.org/10.1016/j.wasman.2019.06.023

Economic Development Winnipeg. (2016). Economic Performance Indicators Economic Development Winnipeg Inc. https://web. archive.org/web/20160310055419/http://www.economicdevelop mentwinnipeg.com/uploads/document_file/2013_economic_perfo rmance_indicators.pdf? $\mathrm{t}=1397601473$. Accessed 2 Jan 2020

Economic Development Winnipeg. (2019). Data Tables I Economic Development Winnipeg. https://www.economicdevelopmentw innipeg.com/site-selection/data-tables. Accessed 2 Jan 2020
Ferronato N, Moresco L, Guisbert Lizarazu GE, Gorritty Portillo MA, Conti F, Torretta V (2021) Comparison of environmental impactsrelated to municipal solid waste and construction and demolition waste management and recycling in a Latin American developing city. Environ Sci Pollut Res 1-15

Ferronato N, Portugal Alarcón GP, Guisbert Lizarazu EG, Torretta V (2020) Assessment of municipal solid waste collection in Bolivia: Perspectives for avoiding uncontrolled disposal and boosting waste recycling options. Resour Conserv Recycl. https://doi.org/ 10.1016/j.resconrec.2020.105234

Ghinea C, Drăgoi EN, Comăniţă ED, Gavrilescu M, Câmpean T, Curteanu S, Gavrilescu M (2016) Forecasting municipal solid waste generation using prognostic tools and regression analysis. J Environ Manag 182:80-93. https://doi.org/10.1016/j.jenvman.2016. 07.026

Golbaz S, Nabizadeh R, Sajadi HS (2019) Comparative study of predicting hospital solid waste generation using multiple linear regression and artificial intelligence. J Environ Health Sci Eng 17(1):41-51. https://doi.org/10.1007/s40201-018-00324-z

Islam MR, Ali SM, Fathollahi-Fard AM, Kabir G (2021) A novel particle swarm optimization-based grey model for the prediction of warehouse performance. J Comp Des Eng 8(2):705-727. https:// doi.org/10.1093/jcde/qwab009

Javed SA, Ikram M, Tao L, Liu S (2020) Forecasting key indicators of China's inbound and outbound tourism: optimistic-pessimistic method. Grey Syst: Theory Appl, ahead-of-p(ahead-of-print). https://doi.org/10.1108/gs-12-2019-0064

Kamarehie B, Jafari A, Ghaderpoori M, Azimi F, Faridan M, Sharafi K, Karami MA (2020) Qualitative and quantitative analysis ofmunicipal solid waste in Iran for implementation of best waste management practice: a systematic review and meta-analysis. Environ Sci Pollut Res 1-13

Kannangara M, Dua R, Ahmadi L, Bensebaa F (2018) Modeling and prediction of regional municipal solid waste generation and diversion in Canada using machine learning approaches. Waste Manag 74:3-15. https://doi.org/10.1016/j.wasman.2017.11.057

Kayacan E, Ulutas B, Kaynak O (2010) Grey system theory-based models in time series prediction. Expert Syst Appl 37(2):17841789. https://doi.org/10.1016/j.eswa.2009.07.064

Khan D, Kumar A, Samadder SR (2016) Impact of socioeconomic status on municipal solid waste generation rate. Waste Manag 49:15-25. https://doi.org/10.1016/j.wasman.2016.01.019

Kolekar KA, Hazra T, Chakrabarty SN (2016) A Review on Prediction of Municipal Solid Waste Generation Models. Procedia Environ Sci 35:238-244. https://doi.org/10.1016/j.proenv.2016.07.087

Kontokosta CE, Hong B, Johnson NE, Starobin D (2018) Using machine learning and small area estimation to predict buildinglevel municipal solid waste generation in cities. Comput Environ Urban Syst 70(March):151-162. https://doi.org/10.1016/j.compe nvurbsys.2018.03.004

Kumar A, Samadder SR (2017) An empirical model for prediction of household solid waste generation rate - A case study of Dhanbad, India. Waste Manag 68:3-15. https://doi.org/10.1016/j.wasman. 2017.07.034

Kurniawan TA, Lo W, Singh D, Dzarfan Othman MH, Avtar R, Hwang GH, Albadarin AB, Kern AO, Shirazian S (2021) A societal transition of MSWM in Xiamen (China) toward a circular economy through integrated waste recycling and technological digitization. Environ Pollut 277:116741. https://doi.org/10.1016/j.envpol.2021. 116741

Lee RP, Meyer B, Huang Q, Voss R (2020) Sustainable waste management for zero waste cities in China: Potential, challenges andopportunities. Clean Energy 4(3):169-201. https://doi.org/10.1093/ ce/zkaa013 
Li K, Zhang T (2019) A novel grey forecasting model and its application in forecasting the energy consumption in Shanghai. Energy Syst. https://doi.org/10.1007/s12667-019-00344-0

Liu S, Forrest J, \& Yang Y (2011). A brief introduction to grey systems theory. Proceedings of 2011 IEEE International Conference on Grey Systems and Intelligent Services, GSIS'11 - Joint with the 15th WOSC International Congress on Cybernetics and Systems, 1-9. https://doi.org/10.1109/GSIS.2011.6044018

Liu F, Wen Z, Xu Y (2013) A dual-uncertainty-based chance-constrained model for municipal solid waste management. Appl Math Model 37(22):9147-9159. https://doi.org/10.1016/j.apm. 2013.04.036

Liu S, Yang Y, Forrest J (2016) Grey Data Analysis, (1st) edn. Springer, New York

Liu B, Zhang L, Wang Q (2021) Demand gap analysis of municipal solid waste landfill in Beijing: Based on the municipal solid waste generation. Waste Manag 134(April):42-51. https://doi. org/10.1016/j.wasman.2021.08.007

Llanquileo-Melgarejo P, Molinos-Senante M (2021) Evaluation of economies of scale in eco-efficiency of municipal waste management: anempirical approach for Chile. Environ Sci Pollut Res 28(22):28337-28348

Lombardi E, \& Bailey K (2015). The Community Zero Waste Roadmap. Eco-Cycle Solutions. https://static1.squarespace.com/ static/56defd4d044262eeaf72a5c8/t/570c1b95cf80a178016c 4d68/1460411334466/Community_Zero_Waste_RoadmapEcoCycle_2015-2.pdf. Accessed 2 Jan 2020

Lu SL (2019) Integrating heuristic time series with modified grey forecasting for renewable energy in Taiwan. Renew Energy 133:1436-1444. https://doi.org/10.1016/j.renene.2018.08.092

Lü X, Lu W (2012) Pre-alarm model of diesel vapour detection and alarm based on grey forecasting. Measurement: Journal of the International Measurement Confederation 45(4):656-662. https://doi.org/10.1016/j.measurement.2012.01.003

Madden B, Florin N, Mohr S, Giurco D (2019) Using the waste Kuznet's curve to explore regional variation in the decoupling of waste generation and socioeconomic indicators. Resour Conserv Recycl 149(March):674-686. https://doi.org/10.1016/j. resconrec.2019.06.025

Madhi MH, Mohamed N (2016) An Improved GM(1,1) Model Based on Modified Background Value. Inf Technol J 16(1):11-16. https://doi.org/10.3923/itj.2017.11.16

Moazzem S, Wang L, Daver F, Crossin E (2021) Environmental impact of discarded apparel landfilling and recycling. Resour Conserv Recycl 166:105338. https://doi.org/10.1016/j.resco nrec.2020.105338

Mohammadi M, Jämsä-Jounela SL, Harjunkoski I (2019) Optimal planning of municipal solid waste management systems in an integrated supply chain network. Comput Chem Eng 123:155169. https://doi.org/10.1016/j.compchemeng.2018.12.022

Mushtaq J, Dar AQ, Ahsan N (2020a) Physio-chemical characterization of municipal solid waste and its management in highaltitude urban areas of North-Western Himalayas. Waste Disposa Sustain Energy 2(2):151-160. https://doi.org/10.1007/ s42768-020-00040-1

Mushtaq J, Dar AQ, Ahsan N (2020b) Spatial-temporal variations and forecasting analysis of municipal solid waste in the mountainous city of north-western Himalayas. SN Appl Sci 2(7):1-18. https://doi.org/10.1007/s42452-020-2975-x

Nguyen XC, Nguyen TTH, La DD, Kumar G, Rene ER, Nguyen DD, Chang SW, Chung WJ, Nguyen XH, Nguyen VK (2021) Development of machine learning - based models to forecast solid waste generation in residential areas: A case study from Vietnam. Resour Conserv Recycl 167:105381. https://doi.org/ 10.1016/j.resconrec.2020.105381
Niska H, Serkkola A (2018) Data analytics approach to create waste generation profiles for waste management and collection. Waste Manag 77:477-485. https://doi.org/10.1016/j.wasman.2018.04. 033

Pan C, Bolingbroke D, Ng KTW, Richter A, Vu HL (2019) The use of waste diversion indices on the analysis of Canadian waste management models. J Mater Cycles Waste Manag 21(3):478-487. https://doi.org/10.1007/s10163-018-0809-3

Pecorini I, Peruzzi E, Albini E, Doni S, Macci C, Masciandaro G, Iannelli R (2020) Evaluation of MSW compost and digestate mixtures for a circular economy application. Sustainability (Switzerland) 12(7):3042. https://doi.org/10.3390/su12073042

Qiao X, Zhang Z, Jiang X, He Y, Li X (2019) Application of grey theory in pollution prediction on insulator surface in power systems. Eng Fail Anal 106:104153. https://doi.org/10.1016/j.engfa ilanal.2019.104153

Rahman MH, Tumpa TJ, Ali SM, Paul SK (2019) A grey approach to predicting healthcare performance. Measurement: Journal of the International Measurement Confederation 134(October):307-325. https://doi.org/10.1016/j.measurement.2018.10.055

Rathore P, Sarmah SP (2020) Economic, environmental and social optimization of solid waste management in the context of circular economy. Comput Ind Eng 145(May):106510. https://doi.org/10. 1016/j.cie.2020.106510

Ren J (2018) GM(1,N) method for the prediction of anaerobic digestion system and sensitivity analysis of influential factors. Bioresour Technol 247(October):1258-1261. https://doi.org/10.1016/j.biort ech.2017.10.029

Ren J, Gao S, Tan S, Dong L (2013) Prediction of the yield of biohydrogen under scanty data conditions based on $\mathrm{GM}(1, \mathrm{~N})$. Int $\mathrm{J}$ Hydrog Energy 38(30):13198-13203. https://doi.org/10.1016/j. ijhydene.2013.07.081

Richter A, Ng KTW, Pan C (2018) Effects of percent operating expenditure on Canadian non-hazardous waste diversion. Sustain Cities Soc 38:420-428. https://doi.org/10.1016/j.scs.2018.01.026

Richter A, Ng KTW, Vu HL, Kabir G (2021a) Waste disposal characteristics and data variability in a mid-sized Canadian city during COVID-19. Waste Manag 122:49-54. https://doi.org/10.1016/j. wasman.2021.01.004

Richter A, Ng KTW, Vu HL, Kabir G (2021b) Identification of behaviour patterns in waste collection and disposal during the first wave of COVID-19 in Regina, Saskatchewan. Canada J Environ Manag 290:112663. https://doi.org/10.1016/j.jenvman.2021.112663

Singh A (2019) Managing the uncertainty problems of municipal solid waste disposal. J Environ Manag 240(December 2018):259-265. https://doi.org/10.1016/j.jenvman.2019.03.025

Singh D, Satija A (2016) Municipal solid waste generation forecasting for faridabad city located in Haryana state, India. Adv Intell Syst Comp 437:285-292. https://doi.org/10.1007/978-981-10-04513_27

Solano Meza JK, Orjuela Yepes D, Rodrigo-Ilarri J, Cassiraga E (2019) Predictive analysis of urban waste generation for the city of Bogotá, Colombia, through the implementation of decision trees-based machine learning, support vector machines and artificial neural networks. Heliyon 5(11):e02810. https://doi.org/10. 1016/j.heliyon.2019.e02810

Sousa SIV, Martins FG, Alvim-Ferraz MCM, Pereira MC (2007) Multiple linear regression and artificial neural networks based on principal components to predict ozone concentrations. Environ Model Softw 22(1):97-103. https://doi.org/10.1016/j.envso ft.2005.12.002

Statistics Canada. (2011). Focus on Geography Series, 2011 Census Census subdivision of Winnipeg, CY (Manitoba). https://www12. statcan.gc.ca/census-recensement/2011/as-sa/fogs-spg/Facts-csdeng.cfm?LANG $=$ Eng\&GK $=C S D \& G C=4611040$. Accessed 2 Jan 2020 
Statistics Canada. (2016). Census Profile, 2016 Census - Winnipeg, City [Census subdivision], Manitoba and Canada [Country]. https://www12.statcan.gc.ca/census-recensement/2016/dp$\mathrm{pd} /$ prof/details/page.cfm?Lang $=\mathrm{E} \& \mathrm{Geo} 1=\mathrm{CSD} \&$ Code $1=46110$ $40 \&$ Geo $2=$ PR $\&$ Code $2=01 \&$ Data $=$ Count $\&$ SearchText $=46110$ $40 \&$ SearchType $=$ Begins $\&$ SearchPR $=01 \& B 1=$ All $\&$ Custom $=\&$ TABID $=3$. Accessed 2 Jan 2020

Tealab A (2018) Time series forecasting using artificial neural networks methodologies: A systematic review. Future Comp Inform J 3(2):334-340. https://doi.org/10.1016/j.fcij.2018.10.003

Tsai FM, Bui TD, Tseng ML, Wu KJ (2020) A causal municipal solid waste management model for sustainable cities in Vietnam under uncertainty: A comparison. Resour Conserv Recycl 154(November 2019):104599. https://doi.org/10.1016/j.resconrec.2019. 104599

Vu HL, Ng KTW, Bolingbroke D (2019) Time-lagged effects of weekly climatic and socio-economic factors on ANN municipal yard waste prediction models. Waste Manag 84:129-140. https://doi. org/10.1016/j.wasman.2018.11.038

Vu HL, Ng KTW, Richter A, Karimi N, Kabir G (2021) Modeling of municipal waste disposal rates during COVID-19 using separated waste fraction models. Sci Total Environ 789:148024. https://doi. org/10.1016/j.scitotenv.2021.148024

Wang Q, Song X (2019) Forecasting China's oil consumption: A comparison of novel nonlinear-dynamic grey model (GM), linear GM, nonlinear GM and metabolism GM. Energy 183:160-171. https:// doi.org/10.1016/j.energy.2019.06.139

Wang H, Dong X, Li Q, Ren Z (2018) Confidence assessment and interval prediction for multi-input model via grey system theory. Grey Syst: Theory Appl 8(1):69-83. https://doi.org/10.1108/ gs-07-2017-0024

Weather Atlas. (2020). Winnipeg, Canada - Detailed climate information and monthly weather forecast I Weather Atlas. https://www. weather-ca.com/en/canada/winnipeg-climate. Accessed 2 Jan 2020

Weatherstats. (2020). Weather Data Download for Winnipeg. https:// winnipeg.weatherstats.ca/download.html. Accessed 2 Jan 2020
Wei Y, Xue Y, Yin J, Ni W (2013) Prediction of municipal solid waste generation in china by multiple linear regression method. Int $\mathbf{J}$ Comput Appl 35(3):136-140. https://doi.org/10.2316/Journal.202. 2013.3.202-3898

Xiao S, Dong H, Geng Y, Francisco MJ, Pan H, Wu F (2020) An overview of the municipal solid waste management modes andinnovations in Shanghai, China. Environ Sci Pollut Res 27(24):29943-29953

Younes MK, Nopiah ZM, Basri NEA, Basri H, Abushammala MFM, Kna M (2015) Solid waste forecasting using modified ANFIS modeling. J Air Waste Manag Assoc 65(10):1229-1238. https:// doi.org/10.1080/10962247.2015.1075919

Younes MK, Nopiah ZM, Basri NEA, Basri H, Abushammala MFM, Younes MY (2016) Landfill area estimation based on integrated waste disposal options and solid waste forecasting using modified ANFIS model. Waste Manag 55:3-11. https://doi.org/10.1016/j. wasman.2015.10.020

Zaman AU (2015) A comprehensive review of the development of zero waste management: Lessons learned and guidelines. J Clean Prod 91:12-25. https://doi.org/10.1016/j.jclepro.2014.12.013

Zeng B, Ma X, Shi J (2020) Modeling Method of the Grey $\operatorname{GM}(1,1)$ Model with Interval Grey Action Quantity and Its Application. Complexity 2020(c):1-10. https://doi.org/10.1155/2020/6514236

Zhang, Y., Mazza, A., Colella, P., Bompard, E., Roggero, E., \& Galofaro, G. (2019). Prediction of Power Outages in Distribution Network with Grey Theory. SEST 2019-2nd International Conference on Smart Energy Systems and Technologies, 1-5. https://doi.org/ 10.1109/SEST.2019.8849044

Publisher's note Springer Nature remains neutral with regard to jurisdictional claims in published maps and institutional affiliations. 